\title{
Chemocatalytic Amplification Probes Enable Transcriptionally-Regulated Au(I)-Catalysis in E. coli and Sensitive Detection of SARS-CoV-2 RNA Fragments
}

\author{
Sydnee A. Green, Benjamin Wigman, Sepand K. Nistanaki, Hayden R. Montgomery,
}

Christopher G. Jones, Hosea M. Nelson*

Department of Chemistry and Biochemistry, University of California, Los Angeles, Los Angeles, CA, 90095, USA

*Corresponding Author Email: hosea@chem.ucla.edu (H.M.N.)

\section{Abstract:}

The union of transition metal catalysis with native biochemistry presents a powerful opportunity to perform abiotic reactions within complex biological systems $(1,2)$. However, several chemical compatibility challenges associated with incorporating reactive metal centers into complex biological environments have hindered efforts in this area, despite the many opportunities it may present. More challenging than chemical compatibility is biocommunicative transition metal catalysis, where the reactivity of the metal species is regulated by native biological stimuli, akin to natural biocatalytic processes. Here we report a novel $\mathrm{Au}(\mathrm{I})$-DNAzyme that is activated by short nucleic acids in a highly sequence-specific manner and that is compatible with complex biological matrices. The active $\mathrm{Au}(\mathrm{I})$-DNAzyme catalyzes the formation of a fluorescent molecule with $>10$ turnovers. This functional allostery, resulting in chemocatalytic signal amplification, is competent in complex biological settings, including within recombinant E. coli cells, where the catalytic activity of the $\mathrm{Au}(\mathrm{I})$-DNAzyme is regulated by transcription of an inducible plasmid. We further demonstrate the potential of this transition metal oligonucleotide complex as a highly sensitive and selective hybridization probe, permitting the detection of attomolar concentrations ( $c a$. 60 molecules $/ \mu \mathrm{L}$ ) of SARS-CoV-2 RNA gene fragments in simulated biological matrices with $\geq 85 \%$ 
accuracy. Notably, this sensitive detection platform avoids expensive and poorly-scalable biochemical components (e.g. post-synthetically modified oligonucleotides or enzymes) and instead utilizes small molecule fluorophores, inexpensive Au salts and oligonucleotides composed of canonical bases. This discovery highlights promising opportunities to perform abiotic catalysis in complex biological settings under transcriptional regulation, as well as a chemocatalytic strategy for PCR-free, direct-detection of RNA and DNA.

\section{Introduction:}

While transition metal catalysis has become a powerful and efficient tool in synthetic chemistry, its application in biology has trailed behind, as synthetic transition metal complexes struggle to avoid deleterious reactions with the diverse chemical functionalities present in biological media. The biocatalytic community has made great strides toward overcoming this challenge, demonstrating that engineering of wild-type metalloenzymes can lead to biocatalysts that mediate abiotic chemical transformations such as insertion and other metal-carbenoid reactions (2). In fewer examples, novel metalloenzymes with non-native metal centers have been reported, in some cases capable of mediating transformations well beyond the scope of wild-type biochemical transformations (3-6). Organometallic complexes have also found use in biological settings, although rarely employed catalytically $(8-10)$.

Our group has become interested in developing transition metal catalysts that are not only functional under the challenge of biological conditions, but also regulated by gene transcription. In this scenario, we envisioned genotype-specific catalysis, where bioconjugation reactions and activation of pro-drugs or reporter molecules could be controlled temporally and spatially through transcriptional upregulation. Moreover, akin to biochemical amplification regimes such as polymerase chain reaction (PCR), we envisioned that signal amplification could be achieved 
through this chemical catalysis, allowing for detection of infinitesimally-small quantities of gene transcripts for applications in chemical biology, genetics, and diagnostics. To this end, we previously reported an example of a novel $\mathrm{Au}(\mathrm{I})$-DNAzyme that performs abiotic hydroamination reactions under highly sequence specific upregulation by short RNA or DNA fragments (Figure 1) (11). In the initial study, we provided proof-of-principle, but were not able to demonstrate efficacy in biological matrices as our Au(I)-DNAzyme proved to be poorly compatible with biological media. Herein we report the development of a new Au(I)-DNAzyme scaffold featuring a novel metal-binding motif comprised of a $\mathrm{Au}(\mathrm{I})$-mediated cytosine-cytosine $(\mathrm{C}-\mathrm{C})$ base pair

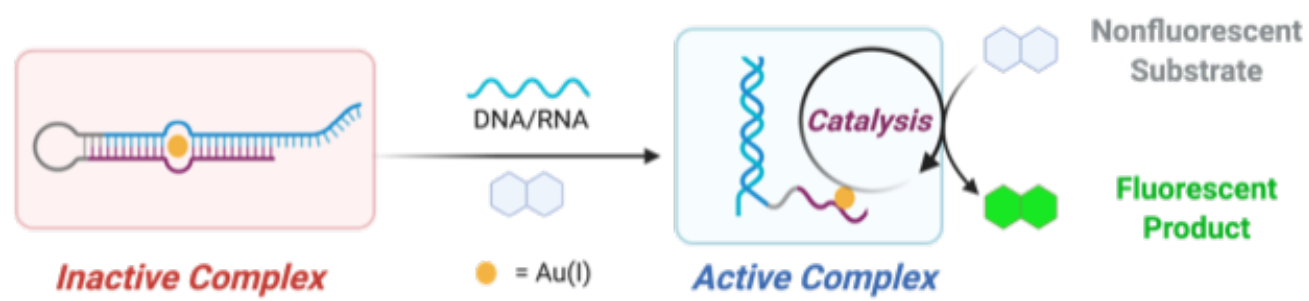

Figure 1. Activation of $\mathrm{Au}(\mathrm{I})-\mathrm{CAP}$ with complementary DNA or RNA transcript.

with unprecedented thermal and biological stability. We show that this new Au(I)-DNAzyme is capable of catalyzing Friedel-Crafts-like reactions of alkynes in response to gene transcription in cellular extracts and inside living E. coli cells. We further demonstrate the application of this strategy to diagnostics, as we are able to directly detect attomolar ( $c a .60$ molecules $/ \mu \mathrm{L})$ quantities of RNA ( $\geq 85 \%$ accuracy). This is highlighted by the PCR-free, direct detection of SARS-CoV-2 RNA fragments in simulated saliva samples using our chemocatalytic amplification probes (CAPs).

\section{Results and Discussion:}

In previous studies we found that a $\mathrm{Au}(\mathrm{I}) \mathrm{DNA}$ complex could be formed through the incorporation of $\mathrm{Au}(\mathrm{I})$ into a DNA duplex containing a $\mathrm{C}-\mathrm{T}$ mismatch, thereby increasing the thermal stability 
of the duplex by $7{ }^{\circ} \mathrm{C}(11)$. At the outset of this current study, we hypothesized that other pyrimidine mismatches might also bind $\mathrm{Au}(\mathrm{I})$ ions in a similar fashion. Through thermal stability studies we ultimately discovered that DNA duplexes containing a $\mathrm{C}-\mathrm{C}$ mismatch were significantly stabilized upon the addition of a $\mathrm{Au}(\mathrm{I})$ precursor $\left(\mathrm{Me}_{2} \mathrm{SAuCl}\right)$, suggesting the formation of a stabilizing $\mathrm{C}-\mathrm{Au}-\mathrm{C}$ metal-mediated base pair (MMBP). Interestingly, treating DNA duplex $\mathbf{C C 1}$ with two equivalents of $\mathrm{Au}(\mathrm{I})$ resulted in a large increase in thermal stability $\left(\Delta T_{\mathrm{m}}=\right.$ $33{ }^{\circ} \mathrm{C}$ ), which was significant compared to the addition of only one equivalent of $\mathrm{Au}(\mathrm{I})$ (Figure 2). The addition of greater than two equivalents of $\mathrm{Au}(\mathrm{I}) \mathrm{had}$ minimal effect, and the corresponding "matched" C-G (CG1) or A-T (AT1) DNA sequences were also essentially unaffected by the addition of $\mathrm{Au}(\mathrm{I})$. These experiments suggest the selective incorporation of two $\mathrm{Au}(\mathrm{I})$ ions into a

a)

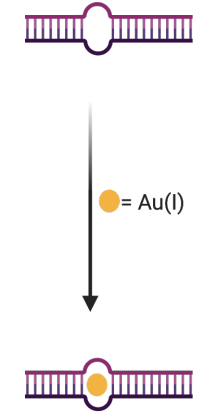

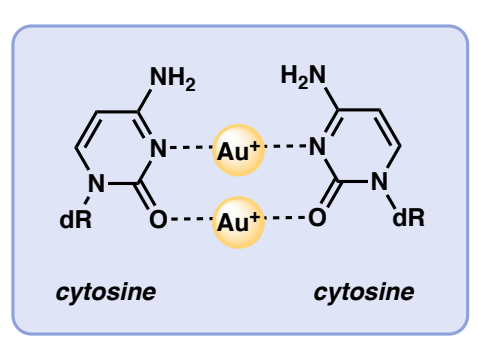

b)

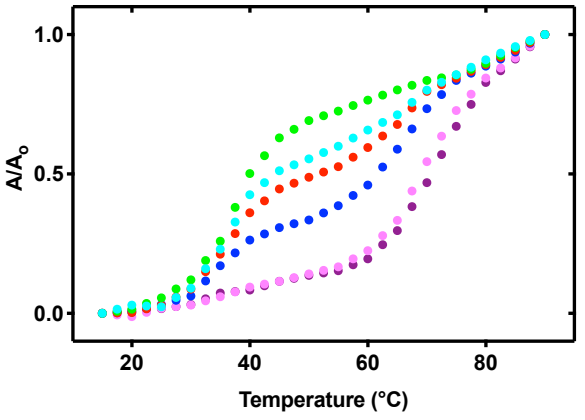

$T_{m}\left({ }^{\circ} \mathrm{C}\right)$ with $\mathrm{n}$ equiv of $\left(\mathrm{Me}_{2} \mathrm{~S}\right) \mathrm{AuCl}$

c)

\begin{tabular}{|c|c|c|c|c|c|c|}
\hline \multirow[b]{2}{*}{ entry } & \multirow[b]{2}{*}{ duplex } & & \\
\hline & & & $n=0$ & $n=1$ & $n=2$ & $\Delta T_{\mathrm{m}}\left({ }^{\circ} \mathrm{C}\right)$ \\
\hline 1 & $\begin{array}{l}\text { 5'-d(CCT TTC TCT CCC TC) } \\
\text { 3'-d(GGA AAG AGA GGG AG) }\end{array}$ & CG1 & $55.6 \pm 0.3$ & $60.0 \pm 0.5$ & - & $4.4 \pm 0.6^{a}$ \\
\hline 2 & $\begin{array}{l}\text { 5'-d(CCT TTC TAT CCC TC) } \\
\text { 3'-d(GGA AAG ATA GGG AG) }\end{array}$ & AT1 & $52.4 \pm 0.3$ & $53.8 \pm 0.3$ & - & $1.4 \pm 0.4$ \\
\hline 3 & $\begin{array}{l}\text { 5'-d(CCT TTC TCT CCC TC) } \\
\text { 3'-d(GGA AAG ACA GGG AG) }\end{array}$ & Cc1 & $38.3 \pm 0.9$ & $\begin{array}{l}35.2 \pm 0.8 \\
67.1 \pm 1.4^{b}\end{array}$ & $71 \pm 1$ & $33 \pm 3$ \\
\hline
\end{tabular}

Figure 2. a) Thermal denaturation curves for $\mathrm{CC} 1$ duplex with varying equivalents of $\mathrm{Au}(\mathrm{I})$ $(0,0.4,1.0,1.4,2.0,3.0)\left(\bullet 0\right.$ equiv. $\left(\mathrm{Me}_{2} \mathrm{~S}\right) \mathrm{AuCl}, \bullet 0.4$ equiv. $\left(\mathrm{Me}_{2} \mathrm{~S}\right) \mathrm{AuCl}, \bullet 1.0$ equiv. $\left(\mathrm{Me}_{2} \mathrm{~S}\right) \mathrm{AuCl}, \bullet 1.4$ equiv. $\left(\mathrm{Me}_{2} \mathrm{~S}\right) \mathrm{AuCl}, \bullet 2.0$ equiv. $\left(\mathrm{Me}_{2} \mathrm{~S}\right) \mathrm{AuCl}, \cdot 3.0$ equiv. $\left.\left(\mathrm{Me}_{2} \mathrm{~S}\right) \mathrm{AuCl}\right)$. b) Addition of $\left(\mathrm{Me}_{2} \mathrm{~S}\right) \mathrm{AuCl}$ to DNA mismatch and incorporation of $\mathrm{Au}(\mathrm{I})$ ion c) $T_{\mathrm{m}}$ values

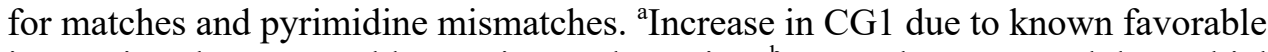
interactions between gold, cytosine, and guanine. ${ }^{\text {b}}$ Two values reported due to biphasic melting. 
$\mathrm{C}-\mathrm{C}$ mismatch. We propose that two $\mathrm{Au}(\mathrm{I})$ ions bind between the endocyclic nitrogens and carbonyl oxygens of the cytosine-cytosine mismatch, based on previous reported structures of $\operatorname{Ag}(\mathrm{I}) \mathrm{MMBPs}$ (Figure 2a) (12,13). This dramatic increase in thermal stability is notable as similar increases have only been observed when synthetic bases are employed or when a covalent cross link has been introduced between the nucleic acid strands (14-16).

Encouraged by the strong binding of $\mathrm{Au}(\mathrm{I})$ to $\mathrm{C}-\mathrm{C}$ mismatches, which implied a potential for greater stability in complex chemical environments, we attempted to incorporate $\mathrm{Au}(\mathrm{I})$ into a hairpin sequence to forge a $\mathrm{Au}(\mathrm{I})$-DNAzyme. We envisioned that two $\mathrm{Au}(\mathrm{I})$ ions could be incorporated into a hairpin sequence containing a single $\mathrm{C}-\mathrm{C}$ mismatch, providing a coordinatively saturated metal complex. Addition of a complementary nucleic acid strand induces strand displacement revealing a coordination site on the metal (Figure 3a). Presumably, binding of alkyne $\mathbf{1}$ to this coordination site initiates cyclization to a fluorescent coumarin product 2 (Figure 3b) (17). In initial experiments, we were pleased to find that activation of a $250 \mathrm{nM}$ solution of the $\mathrm{Au}(\mathrm{I})$-DNA complex with one catalytic equivalent of complement initiated nearly 13 catalytic turnovers based on the concentration of $\mathrm{Au}(\mathrm{I})$ added. Importantly, without addition of the complementary nucleic acid strand, there was approximately 0.1 turnovers (Figure 3c). This finding, though representing modest turnover numbers (TON) from a chemistry perspective, revealed the opportunity to achieve superior sensitivity to our previously reported system due to a dramatic decrease in background reactivity of the probe in the absence of a transcriptional activator (increased signal-to-noise ratio).

With the heightened sensitivity of this probe compared to our previously reported system (250 nM detection vs. $10 \mu \mathrm{M}$ detection), we were compelled to compare the sensitivity of our CAP complexes to molecular beacons routinely used for sensing nucleic acids. Molecular beacons are 
a)

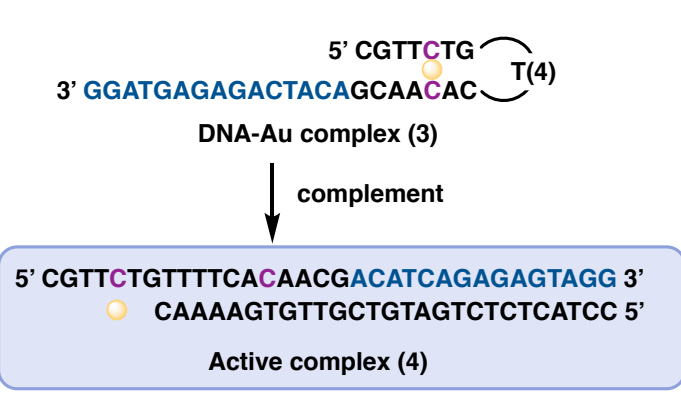

c)

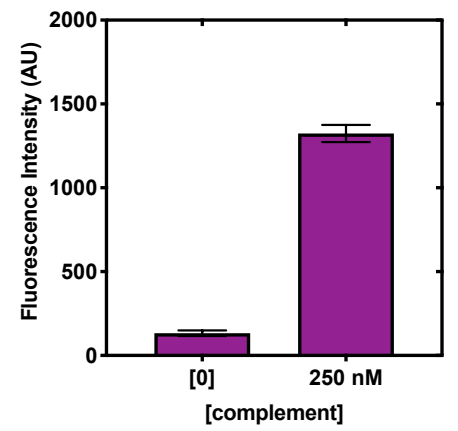

b)

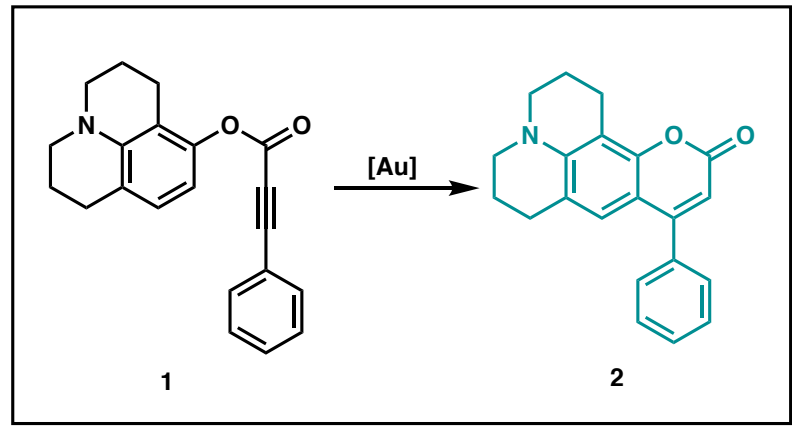

d)

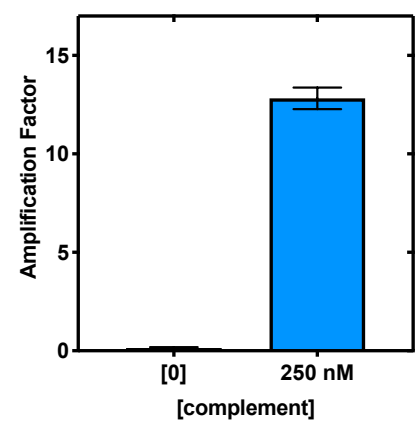

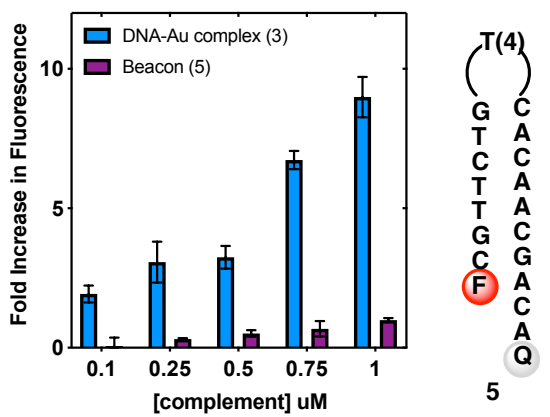

Figure 3. a) Inactive complex 3 hybridizes to complement to form active complex 4. b) Profluorophore 1 cyclizes in presence of gold ions to form fluorescent coumarin product 2. c) Fluorescence intensity and amplification factor of complex $\mathbf{3}$ with profluorophore $\mathbf{1}$. Amplification factor $=[$ fluorescent product]/[complement]. d) Fold increase of DNA-Au complex $\mathbf{3}$ compared to molecular beacon $\mathbf{5}$ with varying concentrations of complement $F=F A M, Q=D A B C Y L$.

often used in conjunction with PCR for quantitative detection of nucleic acids $(18,19)$. These FRET-based probes provide a single fluorescent output for every complementary nucleic acid that is hybridized, hence there is a need for amplification through PCR or other means to increase the amount of detectable nucleic acid present to meet the beacon's limit of detection $(250 \mathrm{nM}$ in our hands) (20). We hypothesized that our catalytic platform could overcome this inherent limitation given its ability to amplify signal through the catalytic production of $>10$ equivalents of fluorophore in response to a single hybridization event. Ultimately, this would allow entry to a more sensitive gene detection platform with improved limits of detection. Indeed, in direct comparison at $1 \mu \mathrm{M}$, addition of one equivalent of complementary sequence led to a 13 -fold increase $($ fold increase $=[$ fluorescence with complement $] /[$ fluorescence with no complement $])$ in fluorescence with the Au(I)-CAP, compared to less than a 2-fold increase with the FRET-based 
molecular beacon. At complement concentrations lower than one equivalent respective to probe, our $\mathrm{Au}(\mathrm{I})$-CAP maintained over a 4-fold increase in fluorescence, whereas the detection limit of the molecular beacon was $\sim 0.25 \mu \mathrm{M}$, above which there was only a 1.3 -fold increase in fluorescence (Figure 3d).

The increased sensitivity of our CAP system inspired us to explore its ability to detect mRNA directly produced through transcription. The direct (PCR-free) detection of mRNA or DNA in cell lysates could contribute to several areas, including diagnostics and forensics, by lowering detection limits. We initially attempted to detect mRNA extracted from recombinant $E$. coli cells. We transformed competent $E$. coli cells with a plasmid containing our complement gene (gene X) and a T7 lac promoter. As an appropriate control, we transformed a group of cells with the plasmid that did not contain gene $\mathrm{X}(21)$. The cell lysate of both cell lines were incubated with our CAP at $1 \mu \mathrm{M}$ and profluorophore 1 at $200 \mu \mathrm{M}$ for 12 hours and subjected to confocal microscopy to visualize fluorescence. We observed that the cell lysate of the cells expressing the complement exhibited nearly a 3-fold increase in fluorescence when compared to the control cell lysate (Figure 4a).

To further assess the ability of our catalyst to perform in biologically relevant conditions, we incorporated the $\mathrm{HP}-\mathrm{Au}(\mathrm{I})$ complex directly into competent E. coli cells using heat shock (Figure 4b) (22). After a three-hour incubation of E. coli transformed with gene X plasmids with $1 \mu \mathrm{M}$ of the $\mathrm{HP}-\mathrm{Au}(\mathrm{I})$ complex, followed by stringent washing, and a subsequent overnight incubation with profluorophore $\mathbf{1}$, we observed that the cells expressing the complementary sequence (Figure 4c) were more fluorescent than the cells containing the control plasmid (Figure 4d). These results further demonstrate the ability of this novel Au(I)-DNAzyme to catalyze abiotic chemical transformations in cellulo in response to gene transcription, highlighting the potential for 
a)

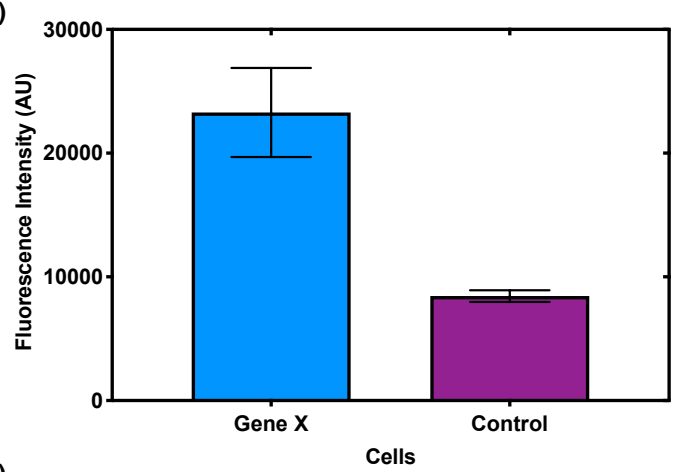

c)

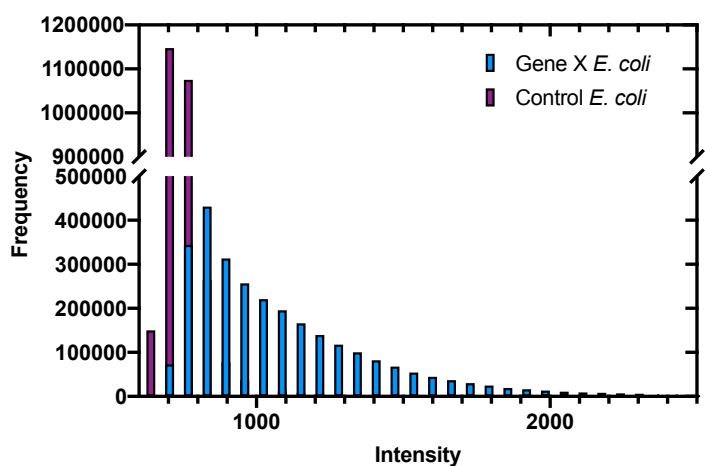

b)

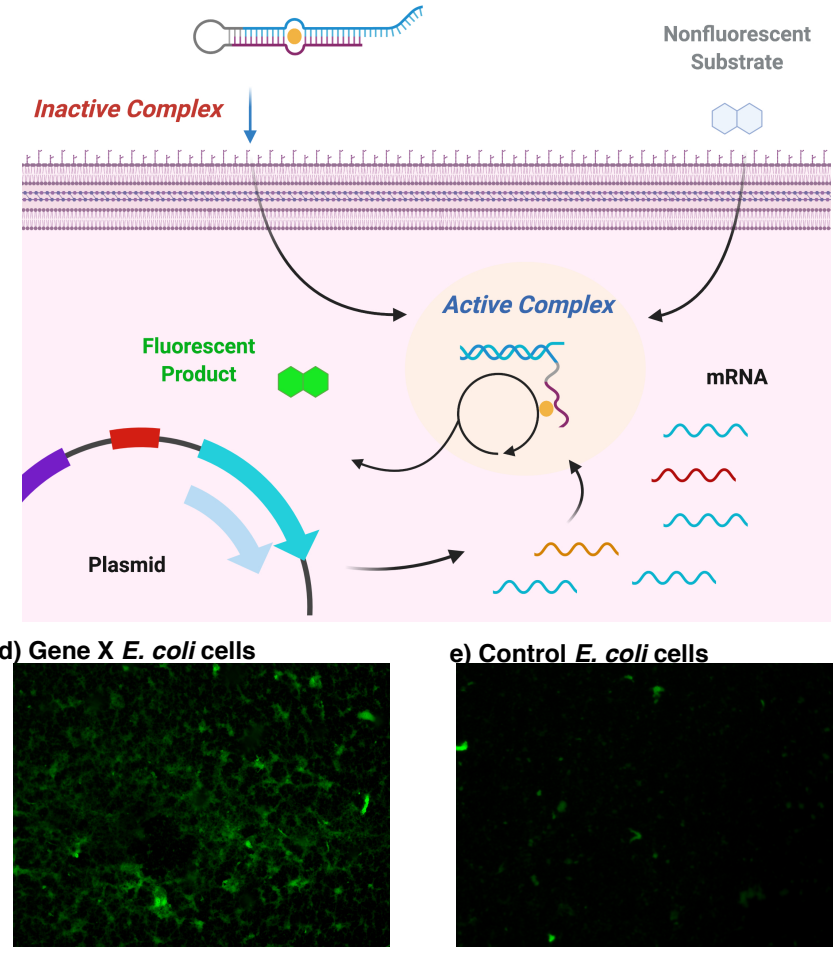

Figure 4. a) Fluorescence intensity in response to gene $X$ and control cell lysates b) Au(I)-CAP incorporation into competent cells engineered to express the complementary sequence. c) Histogram of Frequency vs. Intensity of gene $X$ and control E. coli cell fluorescene d) Fluorescence image of gene $X$ engineered whole cells after incubation with $\mathrm{Au}(\mathrm{I})$-CAP and profluorophore 1. e) Fluorescence image of control whole cells after incubation with $\mathrm{Au}(\mathrm{I})$-CAP and profluorophore 1.

this technology to be used as a highly sensitive diagnostic tool for detection of nucleic acid material in both biotechnological and clinical applications.

Given the remarkable sensitivity of our Au(I)-CAP system for the detection of genetic information under biologically relevant conditions, we reasoned that the application of this technology to viral diagnostics could address an unmet biomedical need. In fact, while developing this system, we were met with the emergence of the COVID-19 pandemic, which highlighted the urgent need for improved diagnostic technologies. In particular, the current testing platform introduced by the Centers for Disease Control (CDC) relies on resource intensive reverse transcription/qPCR to amplify the viral RNA to meet the minimum detection limit of the FRETbased hybridization probe used in the COVID-19 test kit (23). The process requires cumbersome 
procedures, sensitive reagents, and advanced molecular biology instrumentation, thereby limiting rapid deployment of low-cost tests on a large scale, with limited opportunity for point-of-care testing (24). Given these limitations, and the need for accurate, sensitive, and cost-efficient
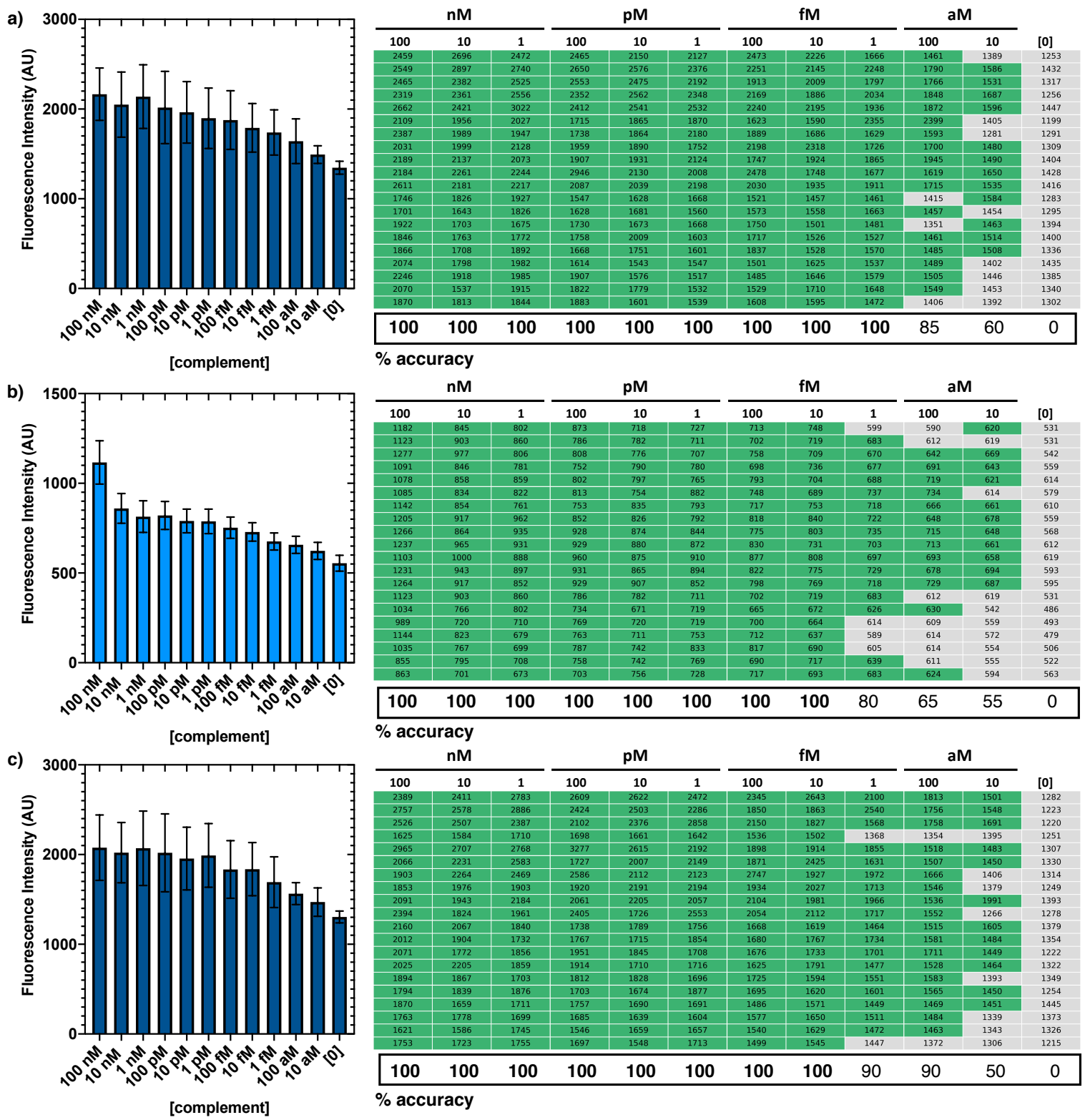

Figure 5. a) Fluorescence intensity of rHP6 with viral RNA fragment in $125 \mathrm{mM} \mathrm{NaClO}_{4}, 4 \%$ synthetic saliva, $10 \mu \mathrm{g} / \mathrm{ml}$ salmon testes DNA and LOD of reactions defined by using 1455 (2 standard deviations above no complement average) as threshold fluorescence after 8 hours. b) Fluorescence intensity of dHP1 with viral DNA reverse transcript in $125 \mathrm{mM} \mathrm{NaClO}_{4}, 4 \%$ synthetic saliva, 10 $\mu \mathrm{g} / \mathrm{ml}$ salmon testes DNA and LOD of reactions defined by using 620 as threshold fluorescence after 4 hours. c) Fluorescence intensity of Hs_RPP30 with RNA transcript in $125 \mathrm{mM} \mathrm{NaClO}_{4}, 4 \%$ synthetic saliva, $10 \mu \mathrm{g} / \mathrm{ml}$ salmon testes DNA and LOD of reactions defined by using as threshold fluorescence after 8 hours. 
COVID-19 diagnostics (25), we felt responsible to translate our newly developed catalytic system toward a COVID-19 diagnostics platform. The observed signal amplification and superior sensitivity of our system over standard molecular beacon platforms highlighted a strategic opportunity to contribute to the field during this unprecedented time.

In initial efforts, we designed several Au(I)-CAPs complementary to various portions of the SARS-CoV-2 genome (see SI). From an examination of hairpin structures that hybridize to the $\mathrm{N}$ gene of the viral genome, hairpin rHP6 (5'-AGT CGC AGC ACA GCT CGC TGG TCC AGA ACT GAT TTT TCA CTT CTG G-3') resulted in a significant increase in fluorescence when exposed to $100 \mathrm{nM}$ of the complementary RNA sequence with $95 \%$ accuracy, using a limit of detection (LOD) threshold analogous to FDA regulations (26). Further comparison of the mean intensities using one-way ANOVA and the Tukey-Kramer Honestly Significant Difference (HSD) test $(\mathrm{p}<0.0001)$ however, show a significant difference in mean intensities down to $10 \mathrm{fM}$ (Figure SX.1) when compared to conditions without the complementary sequence. Given these promising initial experiments, we were eager to see if the rHP6 Au(I)-CAP would be compatible with conditions relevant to real human samples. Interestingly, conducting these experiments in a solution of synthetic saliva containing $10 \mathrm{ug} / \mathrm{mL}$ of random sequence DNA (salmon testes DNA) showed an increase in sensitivity, with $>95 \%$ of the values above the threshold for $1 \mathrm{fM}$ of complementary RNA fragment (Figure 5a). In addition, examination of $\mathrm{Au}(\mathrm{I})$-CAPs complementary to other segments of viral transcript DNA revealed a sequence (dHP1 5'-GAG GGA GCC TTG AAT ACA CCA AAA GAT CAC ATT GGT TTT CCA ATC TGA TC-3') with an LOD of $10 \mathrm{fM}$ (Figure 5b). These sequences outperform the current molecular beacon used in the current CDC test (2019-nCOV_N1 probe - FAM, BHQ-1) in the direct detection 
complementary transcripts (250 $\mathrm{nM}$ in our hands without PCR amplification) by an astounding $10^{7}$-fold increase in sensitivity.

Similar to previously reported COVID-19 detection assays, we designed a $\mathrm{Au}(\mathrm{I})-\mathrm{CAP}$ complex to detect transcripts of the human RNAse P gene as a positive control for RNA extraction $(28,29)$. We found that this $\mathrm{Au}(\mathrm{I})$-CAP (Hs_RPP30 5'-CCG CGC AGA GCC TTC AGG TCA GAA TTT TTT CTC ACC T-3') has exceptional sensitivity and low background reactivity. Akin to our hairpin complex for the SARS-CoV-2 N gene (rHP6), we were able to detect femtomolar (10 $\mathrm{fM}, \geq 95 \%$ accuracy) concentrations of the human RNAse P gene transcript after 2 hours (Figure 5c). Importantly, we found that the addition of short nucleic acid fragments that are noncomplementary to rHP6 or Hs_RPP30 do not result in an increase in fluorescence; Only the addition of the complementary sequence leads to the formation of fluorescent product and therefore selective detection of short nucleic acids can be achieved through this system (29).

Kinetic experiments of rHP6 revealed a significant increase in fluorescence of the solutions containing complement within the first several hours, Figure 6 shows the change in each concentration's probability distribution over time. After the first 60 minutes there is no overlap between $100 \mathrm{nM}$ and the no

a)

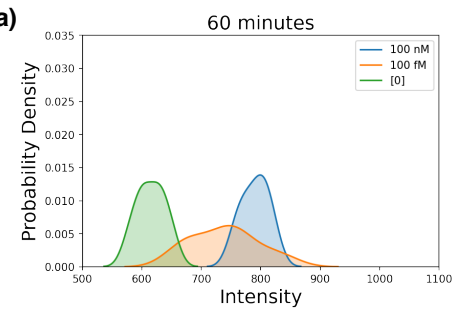

c)

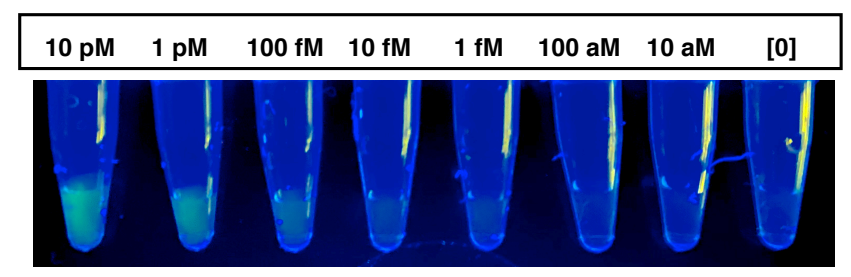

Figure 6. Probability distribution of mean intensities for rHP6 with $100 \mathrm{nM}, 100 \mathrm{fM}$, and [0] of complement DNA at a) 60 minutes and b) 180 minutes. c) Fluorescence of reaction under long wave lamp (390 $\mathrm{nm}$ ) after 36 hours. 
the reactions containing $100 \mathrm{fM}$ of complement have very little overlap with the no complement reactions and are near the LOD (Figure 6b). While at early time points, the fluorescence is fairly low, after 36 hours, the fluorescence differences are visible to the eye under long wave UV irradiation using an inexpensive hand held TLC lamp (Figure 6c). Longer reaction times resulted in an increase in the background from the experiment containing no complement. This background is likely due to leaching of gold and decomposition of the hairpin-Au complex.

\section{Conclusion}

In conclusion, we have discovered and developed a novel $\mathrm{C}-\mathrm{C} \mathrm{MMBP}$, wherein the incorporation of two equivalents of $\mathrm{Au}(\mathrm{I})$ ions results in an unprecedented level of thermal stabilization $\left(\Delta \mathrm{T}_{\mathrm{m}}=\right.$ $\left.33{ }^{\circ} \mathrm{C}\right)$. We have demonstrated that, despite the inherent stability of these Au-DNA complexes, they are able to effectively hybridize to low concentrations of complementary nucleic acid strands, and activate the catalytic activity of the $\mathrm{Au}(\mathrm{I})$ metal center. These findings permitted the detection of low concentrations of mRNA in complex biological matrices such as cell lysates and whole cells, and were competitively more sensitive than standard molecular beacon technologies. This system shows promise as an inexpensive and fast detection method for DNA and RNA. We have demonstrated one such application in the early development of a COVID detection method, which culminated in the ability to detect femtomolar to attomolar concentrations of viral RNA fragments with $\geq 85 \%$ accuracy. Often methods to detect genetic information require expensive enzymes, probes, or instrumentation, however, we have demonstrated the detection of femtomolar concentrations of short nucleic acid transcripts with simple coumarin probes and inexpensive gold salts that could ultimately lead to the development of a cheap and accessible point-of-care viral diagnostics test. We are currently optimizing this system to achieve direct detection of viral genetic information from clinical samples. 


\section{Materials and Methods:}

CAP Enabled Detection of RNA/DNA sequences:

To each well of a black, opaque 100uL polypropylene 96 well plate was added $\mathrm{NaClO}_{4} /$ synthetic saliva solution $\left(20 \mathrm{uL}\right.$, final concentration $165 \mathrm{mM} \mathrm{NaClO}{ }_{4}, 10 \mathrm{ug} / \mathrm{mL}$ exogenous salmon testes DNA). To these wells was added the desired concentration DNA/RNA fragment as an aqueous solution (10 uL). To each well was added a freshly prepared ( $\sim 15$ minutes incubation time) $0.015 \%$ acetone $v / v$ aqueous solution of precomplexed $\mathrm{Me}_{2} \mathrm{~S} \bullet \mathrm{AuCl} / 35$-mer oligonucleotide solution (20uL, final concentration $100 \mathrm{nM}$ ).

To each well was added an $80 \%$ ethanol v/v aqueous solution of the profluorophore (50uL, final concentration $200 \mathrm{uM} 40 \%$ ethanol v/v aqueous solution), 2,3,6,7-tetrahydro- $1 \mathrm{H}, 5 \mathrm{H}$ pyrido[3,2,1-ij]quinolin-8-yl 3-phenylpropiolate, and the solution mixed by pipette (50uL 3 times). The plate was sealed with a clear adhesive cover and allowed to sit at room temperature for the desired time. The cover was removed and the plate was inserted into a Teacan M1000 plate reader. Fluorescence spectra were recorded for each well as an average of 9 readings (420nM Excitation, 535nM Emission, Gain=150, Z-height=24333).

\section{Data Availability.}

Further fluorescence measurements, NMR spectra, cell images, and thermal stability measurements can be found in the SI Appendix.

\section{Acknowledgements.}

Financial support for this work was generously provided by the David and Lucile Packard Foundation (to H.M.N.), the Pew Charitable Trusts (to H.M.N), Bristol Myers Squibb (to H.M.N.), the UCLA AIDS institute (to H.M.N.) and the National Science Foundation (DGE1650604 to B.W. and C.G.J.). S.A.G. thanks the Department of Chemistry and Biochemistry 
UCLA Fellowship for funding. B.W. thanks the Christopher S. Foote Fellowship for funding. S.K.N. thanks the USPHS National Research Service Award (T32GM008496). The authors thank the UCLA Molecular Instrumentation Center for NMR and mass spectrometry instrumentation. This material is based on work supported by the National Institutes of Health under instrumentation (1S10OD016387-01). We would like to thank Dr. Mark Arbing for assistance and the UCLA-DOE Protein Expression Core for E. coli cell transformation and expression. We would like to thank Amir Nasajpour for assistance with cell imaging. We would like to acknowledge Professor F. Dean Toste (UC Berkeley) for useful discussions.

\section{Author Contributions.}

H.M.N. conceived of project and designed experiments. S.A.G., B.W., S.K.N., and H.R.M. designed and conducted experiments. C.G.J. performed statistical analyses. H.M.N., S.A.G., B.W., S.K.N., and C.G.J. prepared the manuscript.

1. H.-T. Hsu, B. M. Trantow, R. M. Waymouth, P. A. Wender, Bioorthogonal Catalysis: A General Method To Evaluate Metal-Catalyzed Reactions in Real Time in Living Systems Using a Cellular Luciferase Reporter System. Bioconjugate Chem. 27, 376-382 (2016).

2. K. Chen, F. H. Arnold, Engineering new catalytic activities in enzymes. Nat. Catal. 3, 203$213(2020)$.

3. M. T-. Gamasa, M. M-. Calvo, J. R. Couceiro, J. L. Mascareñas, Transition metal catalysis in the mitochondria of living cells. Nat. Comm. 7, 12538 (2016). 
6. F. Schwizer et al., Artificial metalloenzymes: reaction scope and optimization strategies.

Chem. Rev. 118, 142-231 (2018).

8. E. V. Vinogradova, C. Zhang, A. M. Spokoyny, B. L. Pentelute, \& S. L. Buchwald, Organometallic palladium reagents for cysteine bioconjugation. Nature 526, 687-691 (2015).

10. C .Streu, E. Meggers, Ruthenium-induced allylcarbamate cleavage in living cells. Angew.

Chem. Int. Ed. 45, 5645-5648 (2006).

11. S. A. Green et al., Regulating transition-metal catalysis through interference by short RNAs. Angew. Chem. Int. Ed. 58, 16400-16404 (2019).

12. A. Ono, et al. Specific interactions between silver(I) ions and cytosine-cytosine pairs in DNA duplexes. Chem. Commun. 10.1039/b808686a, 4825-4827 (2008).

13. A. Ono, H. Torigoe, Y, Tanaka, I. Okamoto, Binding of metal ions by pyrimidine base pairs in DNA duplexes. Chem. Soc. Rev. 40, 5855-5866 (2011).

14. H. Mei, I. Röhl, F Seela, $\mathrm{Ag}^{+}$-mediated DNA base pairing: extraordinarily stable pyrrolo-dCpyrrolo-dC pairs binding two silver ions. J. Org. Chem. 78, 9457-9463 (2013).

16. L. Zhang, E. Meggers, An extremely stable and orthogonal DNA base pair with simplified three-carbon backbone. J. Am. Chem. Soc. 127, 74-75 (2005).

17. J.H. Do, H.N. Kim, Yoon, J., Kim, J. S., H.-J. Kim, A rationally designed fluorescence turnon probe for the Gold(III) ion. Org. Lett. 12, 932-934, (2010).

18. S. Tyagi, F.R. Kramer, Molecular beacons: probes that fluoresce upon hybridization. Nat. Biotechnol. 14, 303-308 (1996).

19. G. Leone, B. van Gemen, C.D. Schoen, H. van Schijndel, F.R. Kramer, Molecular beacon probes combined with amplification by NASBA enable homogeneous, real-time detection of RNA. Nucleic Acids Res. 26, 2150-2155 (1998). 
20. Y. Kim, D. Sohn, W. Tan, Molecular beacons in biomedical detection and clinical Diagnosis. Int. J. Clin. Exp. Pathol. 1, 105-116 (2008).

21. C. Johnston, B. Martin, G. Fichant, P. Polard, J.-P. Claverys, Bacterial transformation: distribution, shared mechanisms and divergent control. Nat. Rev. Microbiol. 12, 181-196 (2014). 22. C. Xi, M. Balberg, S.A. Boppart, L. Raskin, Use of DNA and peptide nucleic acid molecular beacons for detection and quantification of rRNA in solution and in whole cells. Appl. Environ. Microbiol. 69, 5673-5678 (2003).

23. Real-time RT-PCR panel for detection 2019-novel coronavirus. (2020) US Centers for Disease Control and Prevention. https://www.fda.gov/media/134922/download [Accessed 5 July 2020].

24. S. Maddocks, R. Jenkins, "Understanding PCR-Quantitative PCR: Things to Consider" in Understanding PCR: A practical benchtop guide, (Elsevier, 2017), pp 45-52.

25. Y.-W. Tang, J.E. Schmitz, D.H. Persing, C.W. Stratton, Laboratory diagnosis of COVID-19: current issues and challenges. J. Clin. Microbiol. 58, e00512-2 (2020).

28. M. Baer, T. W. Nilsen, C. Costigan, C. Altman, Structure and transcription of a human gene for H1 RNA, the RNA component of human RNase P. Nucleic Acids Res. 18, 97-103 (1990). 29. Diagnostic test for COVID-19 only \& supplies. (2020) Centers for Disease Control and Prevention. https://www.cdc.gov/coronavirus/2019-ncov/lab/virus-requests.html [Accessed 6 July 2020].

29. See SI for details-control with incorrect complements 